Tetik Parmak Cerrahisinde Longitudinal insizyon mu? Transvers insizyon mu?

\title{
Surgical treatment of trigger finger? Longitudinal incision versus transverse incision?
}

Erdinc Acar1 ${ }^{1}$ Ulaş Serarslan²

1 Kocaeli Derince Eğitim ve Araştırma Hastanesi,Ortopedi ve Travmatoloji Kliniği, El cerrahisi Ünitesi, Kocaeli, Türkiye. 2Kocaeli Derince Eğitim ve Araştırma Hastanesi,Ortopedi ve Travmatoloji Kliniği, Kocaeli, Türkiye.

\section{$\ddot{O} Z$}

GíRIŞ ve AMAÇ: Cerrahi uygulanan tetik parmak hastalarında, longitudinal insizyon ile transvers insizyon arasında fark olup olmadı̆̆ı değerlendirildi.

YÖNTEM ve GEREÇLER: Çalışmaya, Kasım 2017 ile Ekim 2018 tarihleri arasinda tetik parmak cerrahisi yapılan 24 hasta (16 bayan, 8 erkek) dahil edildi. Bu hastalar Wolfe sinıflamasına göre değerlendirildi. Bu hastalarda yineleme oranı ve memnuniyet oranları değerlendirildi. Cerrahi sonrası sinir hasarı, yara yeri enfeksiyonu ve yarada açılma gibi komplikasyonlar değerlendirilmiştir.

BULGULAR: Hastaların yaş ortalaması 51,4 (32-72). Wolfe siniflamasina göre $10(\% 41,6)$ olgu evre 2, $14(\% 58,4)$ olgu evre 3 idi. Hastalarn 16 'sl $(\% 66,7)$ bayan, 8 'i $(\% 33,3)$ erkek idi. Hastalar ortalama 8 ay (5-11) takip edildi. Her 2 grupta da yineleme izlenmedi. Hastaların tamamı, cerrahi tedaviden memnun kaldıklarını belirtti.

TARTISSMA ve SONUÇ: Tetik parmak cerrahisi; nüks ve komplikasyon gelişmemesi açısından yararlı bir yöntem olmakla birlikte, uygulanan iki ayrl cerrahi insizyon arasinda fark olmadiğı görüldü.

Anahtar Kelimeler: cerrahi tedavi, longitudinal insizyon, tetik parmak, transvers insizyon

\begin{abstract}
INTRODUCTION: In this study, we aimed to evaluate the efficacy of longitudinal incision versus transverse incision in the surgical treatment of trigger finger.
\end{abstract}

METHODS: Between November 2017 and October 2018, a total of 24 patients who were surgically treated for trigger finger using longitudinal incision or transverse incision were included. Trigger finger was graded according to the Wolfe classification. The rates of recurrence and patient satisfaction were evaluated. Postoperative complications including nerve injury, wound site infection, and wound dehiscence were noted.

RESULTS: Of the patients, $16(66.7 \%)$ were females and 8 (33.3\%) were males with a mean age of 51.4 (range, 32 to 72) years. The mean follow-up was 8 (range, 5 to 11) months. According to the Wolfe classification, 10 patients (41.6\%) had Grade 2 and 14 patients (58.4\%) Grad 3 disease. A longitudinal incision was used in 12 patients (50\%), while a transverse incision was used in 12 patients (50\%). None of the patients had recurrence after surgery. Patient satisfaction was achieved in all patients operated.

DISCUSSION AND CONCLUSION: Our study results suggest that surgical treatment of trigger finger is an effective method without any recurrence or complication and both incision techniques yield similar outcomes.

Keywords: surgical treatment, trigger finger, longitudinal incision, transverse incision.

İletişim / Correspondence:

Dr. Erdinç Acar

Kocaeli Derince Eğitim ve Arașttrma Hastanesi,Ortopedi ve Travmatoloji Kliniği, El cerrahisi Ünitesi, Kocaeli, Türkiye.

E-mail:erdal240@gmail.com

Başvuru Tarihi: 29.10.2018

Kabul Tarihi: 02.04.2019 


\section{GíRiş}

Tetik parmak; fleksor tendonların, içinde hareket ettikleri 1.anüler (A1) pulleyde takılması ile oluşmaktadır (1). Cerrahi tedavi çoğu vakada kesin ve kalıcı bir çözüm sağlamaktadır (2,3). Günümüzde cerrahi insizyon olarak transvers ve/veya longitudinal insizyon tercih edilmektedir (4). Bu çalışmada cerrahi olarak longitudinal insizyon ile transvers insizyon uygulanan hastalar arasinda sinir hasarı, yara yeri enfeksiyonu ve yarada açılma gibi cerrahi sonrası komplikasyonlar açısından ve hastaların memnuniyetleri açısından fark olup olmadığı değerlendirildi.

\section{GEREÇ VE YÖNTEMLER}

Kliniğimizde Kasım/2017 ile Ekim/2018 tarihleri arasında cerrahi uygulanan 24 hasta (16 bayan, 8 erkek) retrospektif (geriye dönük) olarak değerlendirilip, homojen olarak 2 eşit gruba bölündü. 1.grupta 12 hasta (9 bayan, 3 erkek), 2.grupta 12 hasta (7 bayan, 5 erkek) olarak belirlendi. Cerrahi uygulanan 1.gruptaki hastalara longitudinal insizyon, 2.gruptaki hastalara ise transvers insizyon uyguland1. Bütün hastalardan aydınlatılmış onam formu alınmıştır. Hastaların yaş ortalamas1 51,4 (32-72) idi.Tüm hastalar Wolfe sinıflamasına göre değerlendirildi (5). $\mathrm{Bu}$ siniflamaya göre 10 olgu $(\% 41,6)$ evre 2, 14 olgu $(\% 58,4)$ evre 3 idi. Hastaların 16 's $(\% 66,7)$ bayan, 8'i $(\% 33,3)$ erkek idi. Taraf olarak 19 olgu sağ, 5 olgu sol olarak belirlendi (Tablo 1).

\section{Tablo 1.Hastaların demografik ve klinik} verileri

\begin{tabular}{|lll|}
\hline & 1.Grup & 2.Grup \\
\hline Hasta sayıs1 & 12 & 12 \\
\hline Bayan/Erkek & $9 / 3$ & $7 / 5$ \\
\hline Wolfe sinıflamas1 & & \\
Evre 2 & 4 & 6 \\
Evre 3 & 8 & 6 \\
\hline Taraf (Sağ/Sol) & $10 / 2$ & $9 / 3$ \\
\hline
\end{tabular}

14 olgu dördüncü parmak, 5 olgu beşinci parmak, 3 olgu ikinci parmak ve 2 olgu üçüncü parmak olarak belirlendi. 1 vakamızda aynı zamanda karpal tünel sendromu mevcuttu. Aynı seansta median sinir gevşetmesi de uygulandi (Şekil 1).

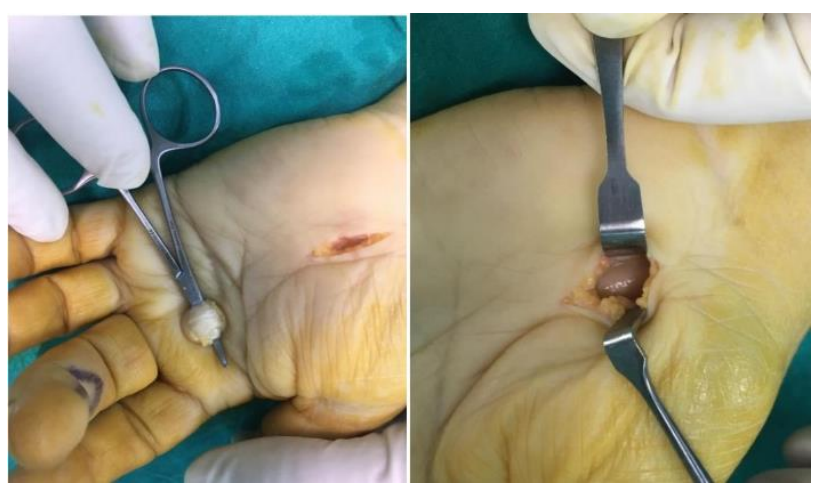

Şekil 1. Intraoperatif 3.tetik parmak ve median sinir gevşetmesi

Hastaların memnuniyet dereceleri 10 üzerinden verdikleri puanlara göre VAS (Vizüel analog skala) skoru kullanılarak değerlendirildi (6). 1-3 arası puan çok kötü, 4-5 puan kötü, 6-7 iyi ve 7 üzeri çok iyi şeklinde puanlandırıldı. Hastalarda sinir hasarı, yara yeri enfeksiyonu ve yarada açılma gibi komplikasyonlar değerlendirilmiştir. Pediatrik tetik parmak hastaları, çoklu tetik parmak hastaları ve tetik başparmak hastaları çalışma dışında tutulmuştur. Çalışmada elde edilen bulgular değerlendirilirken, istatiksel analizler için NCSS ( Number Cruncher Statistical System) 2007 \& PASS ( Performance Analysis of Systems and Software) 2008 software ( Utah, USA) programı kullanıld1. Çalışma verileri değerlendirilirken tanımlayıcı istatiksel metodlar kullanıld1. $\mathrm{p}<0.05$ olması anlamlı kabul edildi.

\section{Cerrahi Teknik}

Cerrahi uygulanan hastalarda standart prosedür olarak rejyonel anestezi (blok) ve turnike altında çalışıldı. Ameliyatlar tek bir cerrah (EA) tarafından gerçekleştirildi. 1.gruptaki hastalara metakarpofalangeal eklem üzerinde $1 \mathrm{~cm}$ lik longitudinal insizyon (Şekil 2), 2.gruptaki hastalara ise transvers insizyonla (Şekil 3) girilerek A1 pulley ekspoze edilip serbestleştirilip hemostaz sonrası cilt kapatıld1. Serbestleştirme sonrası pasif fleksiyon ve ekstansiyon ile tetiklenmenin giderildiğinden ve tendonun hareketlerinin rahatlamış olduğundan emin olundu. Hastalara Bulky (baskılı ve kalın) bandaj sarıld1. Postoperatif erken dönemde (1. gün) hastaların pansumanları parmak hareketlerine 
rahatlıkla izin verecek şekilde küçültüldü ve eklem hareket açıklığını tam korumak için sık mobilizasyon ile ilgili hasta ve hasta yakınlarına ciddi eğitim verildi. Bu eğitimde analjezik ile desteklenerek postoperatif özellikle erken dönemde hastanın parmağını tam fleksiyon - ekstansiyon ve pasif olarak hiperekstansiyona getirmesi üzerinde duruldu.

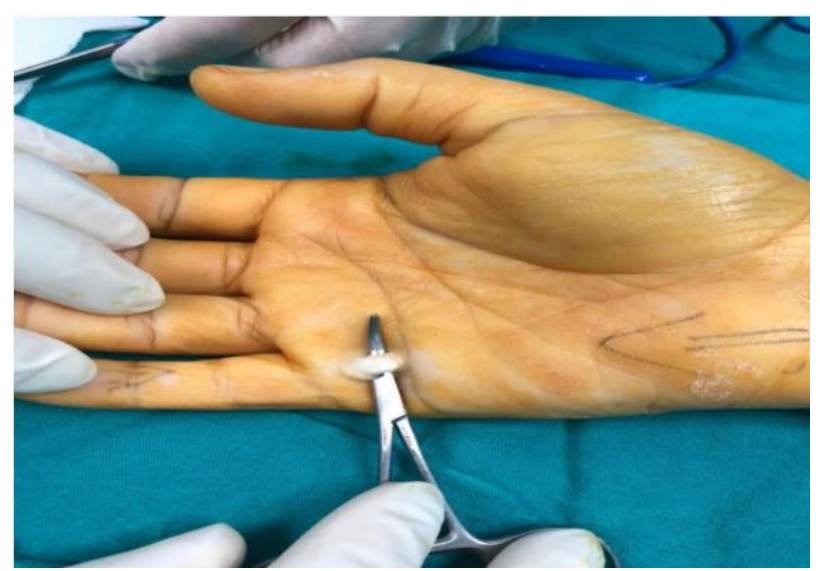

Şekil 2. Intraoperatif 5.tetik parmak longitudinal insizyonla gevşetme

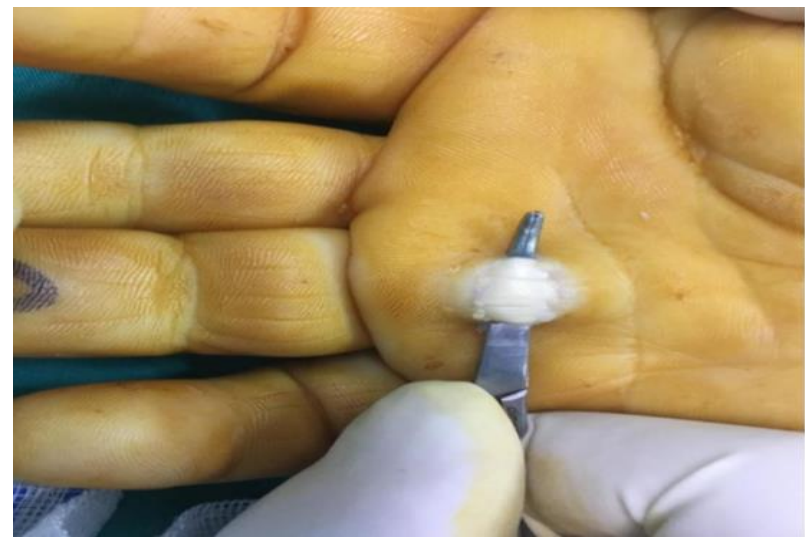

Şekil 3. Intraoperatif 4.tetik parmak transvers insizyonla gevşetme

Ameliyat sonrası dönemde 1 hafta süreyle steroid olmayan antiinflamatuar ilaç ve oral antibiyotik (sefazol tablet 1 gram günde 2 kere/oral) tedavisi verildi. Üç günde bir pansumanları yapıldı. Hastaların postoperatif 3 . haftalarında sütürleri alınd ve 6 . haftada, 12. haftada ve son kontrol olarak görüldü.

\section{BULGULAR}

Hastalar ortalama 8 ay (5-11) takip edildi. Her 2 grupta da yineleme izlenmedi. Her 2 gruptaki hastaların tamamı cerrahi tedaviden memnun kaldıklarını belirttiler ( $\mathrm{p}=0.1)$. 1.grupta 2 hastada skar dokusu gelişmiş olup diğer hastalarda başka bir komplikasyon görülmemiştir.

\section{TARTISSMA}

Tetik parmak, A1 pulleyde kalınlaşma ve fleksor tendonların bu pulleyde takılması ile oluşmaktadır. Histopatolojik olarak da bu hastalarda A1 pulley üzerinde ek bir tabakanın olduğu görülmüştür $(1,7)$. Histopatolojiye bağlı olarak tetik parmak hastalarında, günümüzde giderek artan oranda cerrahi tedavi ön planda yer almıştır $(8,9,10)$. Çalışmamızdaki her 2 hasta grubunda da cerrahi uygulanmıştır. Bazen olgu sunumları olarak karpal tünel sendromu ile tetik parmak birlikteliği literatürde görülmektedir (11). Olgularımızın bir tanesi benzer duruma sahipti.

Tetik parmak cerrahisinde günümüzde uygulanan insizyon şekilleri, transvers ve/veya longitudinal şekilde karşımıza çıkmaktadır (12). Literatürle uyumlu olarak cerrahi insizyonlarımızı 1.gruptaki hastalara longitudinal şekilde, 2.gruptaki hastalara ise transvers şekilde planladık. Kloeters ve ark. yaptkları bir çalışmada; tetik parmak cerrahisinde 3 ayrı insizyon şekli denenmiş olup, sadece distal palmar çizgi üzerindeki transvers insizyonda skar dokusu gelişiminin daha fazla olduğu bulunmuştur. Onun haricinde herhangi bir farklılılık saptanmamıştır (13). Çalışmamızda ise 2 olguda belirgin skar dokusu oluşumu görülmüştür. Literatürde tetik parmak cerrahisi sonrası insizyon şekillerine göre keloid dokusu görülen olgu sunumlar1 mevcuttur (14). Bu olgu sunumunda keloid eksizyonu ve tam kalınlıkta cilt grefti tedavisi uygulandığını görüyoruz. Çalışmamızdaki 2 hastada belirgin skar dokusu gelişmiş olduğu görüldü ve takiplerinde sıkıntı olmadığı görülmüştür.

Tetik parmak cerrahisinde yapılan insizyonlara bağlı major ve minor komplikasyonların geliştiği literatürde görülmüştür. Major komplikasyon nadir olsa da; yara yeri komplikasyonu ve parmak hareket açıklığı kaybı gibi minor komplikasyonlara daha fazla rastlanılmaktadır (15). Çalışmamızda 2 ayrı 
insizyon şekli uygulanmasına rağmen herhangi bir komplikasyon görülmemiştir.

Tetik parmak cerrahisi sonras1 komplikasyonlarda risk faktörü olarak; erkek cinsiyet, ameliyatın sedasyon altında ve genel anestezi altında olması kabul edilmektedir (16). Çalışmamızdaki olguların çoğu bayan olup, ameliyat sirasinda rejyonel anestezi uygulanmasi sebebi ile herhangi bir komplikasyon görülmemiştir.

\section{SONUÇ}

Tetik parmak cerrahisi; nüks ve komplikasyon gelişmemesi açısından güvenli bir yöntem olmakla birlikte, uygulanan iki ayrı cerrahi insizyon arasında cerrahi sonrası komplikasyonlar ve memnuniyet açısından farkın olmadığı görülmüştür. Çalışmamızın sonuçları literatürle uyumlu olarak bulunsa da, olgu sayımızın az olması çalışmamızın kısıtll11 ğı olarak görülmektedir.

\section{KAYNAKLAR}

1. Chuang XL, Ooi CC, Chin ST, Png MA, Wong SK, Tay SC et al. What triggers in trigger finger? The flexor tendons at the flexor digitorum superficialis bifurcation. J Plast Reconstr Aesthet Surg. 2017;70:1411-19.

2. Amirfeyz R, McNinch R, Watts A, Rodrigues $\mathrm{J}$, Davis TRC, Glassey $\mathrm{N}$ et al. Evidence-based management of adult trigger digits. J Hand Surg Eur Vol. 2017;42:473-80.

3. Lim MH, Lim KK, Rasheed MZ, Narayanan $\mathrm{S}$, Beng-Hoi Tan A. Outcome of open trigger digit release. J Hand Surg Eur Vol. 2007;32:457-9.

4. Ger E, Kupcha P, Ger D. The management of trigger thumb in children. J Hand Surg Am. 1991;16:944-7.

5. Wolfe SW. Tenosynovitis. In:Green DP(ed). Operative hand surgery, 5th edition. New York, Churchill Livingstone 2005;2137-59.

6. Copay AG, Glassman SD, Subach BR, Berven S, Schuler TC, Carreon LY. Minimum clinically important difference in lumbar spine surgery patients: a choice of methods using the Oswestry Disability Index, Medical Outcomes Study questionnaire Short Form 36, and Pain Scales. Spine J 2008;8:968-974.

7. Sbernardori MC, Bandiera P. Histopathology of the A1 pulley in adult trigger fingers. J Hand Surg Eur Vol. 2007;32:556-9.
8. Koch AR, Vaandrager JM. Good results with the surgical treatment of trigger finger (tendovaginitis stenosans). Ned Tijdschr Geneeskd. 1991;135:1124-7.

9. Turowski GA, Zdankiewicz PD, Thomson JG. The results of surgical treatment of trigger finger. J Hand Surg Am. 1997;22:145-9.

10. Lange-Riess D, Schuh R, Hönle W, Schuh A. Long-term results of surgical release of trigger finger and trigger thumb in adults. Arch Orthop Trauma Surg. 2009;129:1617-9.

11. Gancarczyk SM, Strauch RJ. Carpal tunnel syndrome and trigger digit: common diagnoses that occur 'hand in hand'. J Hand Surg Am. 2013;38:1635-7.

12. Stefanich RJ, Peimer CA. Longitudinal incision for trigger finger release. J Hand Surg Am. 1989;14:316-7.

13. Kloeters O, Ulrich DJ, Bloemsma G, van Houdt CI. Comparison of three different incision techniques in A1 pulley release on scar tissue formation and postopearative rehabilitation. Arch Orthop Trauma Surg. 2016;136:731-7.

14. Tada K, Suganuma S, Segawa T, Asada N, Tsuchiya H. Keloid formation after trigger finger release: a case report. J Plast Reconstr Aesthet Surg. 2013;66:864-6.

15. Will R, Lubahn J. Complications of open trigger finger release. $\mathrm{J}$ Hand Surg Am. 2010;35:594-6.

16. Everding NG, Bishop GB, Belyea CM, Soong MC. Risk factors for complications of open trigger finger release. Hand (N Y) 2015;10:297-300. 